\title{
Prevalence, risk factors and awareness of albuminuria on a Canadian First Nation: A community-based screening study
}

\author{
James Michael Zacharias ${ }^{1 *}$, T Kue Young ${ }^{2}$, Natalie D Riediger ${ }^{3}$, Joanne Roulette ${ }^{4}$ and Sharon G Bruce ${ }^{3 *}$
}

\begin{abstract}
Background: Both diabetic and non-diabetic end stage renal disease (ESRD) are more common among Canadian First Nations people than among the general Canadian population. The purpose of this research was to determine the prevalence of and risk factors for albuminuria in a Canadian First Nation population at high risk for ESRD and dialysis.

Methods: Data from a community-based screening study of 483 residents of a Plains Ojibway First Nation in Manitoba was used. Participants provided random urine samples. Proteinuria was defined as any dipstick positive for protein ( $\geq 1 \mathrm{~g} / \mathrm{L})$ or those with ACR in the macroalbuminuric range $(\geq 30 \mathrm{mg} / \mathrm{mmol})$ on at least one sample. Microalbuminuria was defined as ACR $\geq 2 \mathrm{mg} / \mathrm{mmol}$ for males and $\geq 2.8 \mathrm{mg} / \mathrm{mmol}$ for females. Other measures included fasting glucose, haemoglobin $A_{1 c}$, triglycerides, cholesterol, blood pressure, height, weight and waist and hip circumferences.
\end{abstract}

Results: Twenty percent of study participants had albuminuria, (5\% proteinuria and 15\% microalbuminuria). Of participants with diabetes, 42\% (56/132) had albuminuria compared to 26\% (7/27) among those with impaired fasting glucose and 10\% (30/303) among those with normal glucose tolerance. Only 5.3\% of those with albuminuria were aware of any degree of renal disease. In a multivariate logistic regression, independent associations with albuminuria were male gender $[p=0.002]$, increasing fasting glucose $[p<0.0001]$, years diagnosed with diabetes $[p=0.03]$, increasing systolic blood pressure $[p=0.009]$, and increasing body mass index (BMI) $[p=0.04]$.

Conclusions: The independent association between BMI and albuminuria has not been previously reported among indigenous populations. There is a high prevalence of albuminuria in this Canadian First Nation population; the high proportion of patients with diabetes and undiagnosed kidney disease demonstrates the need for screening, education and intervention to halt the progression and development of albuminuria and ultimately ESRD and CVD.

Keywords: Canada, First Nation, Albuminuria, End-stage renal disease, Kidney, Diabetes

\section{Background}

The incidence of end-stage renal disease (ESRD) among Canadian First Nations people is 2.5-4 times greater than among the non-First Nations population [1-3] and the most common cause is diabetic nephropathy. The earliest indicator of diabetic renal disease is microalbuminuria [4-10],

\footnotetext{
* Correspondence: jzacharias@exchange.hsc.mb.ca; brucesg@cc.umanitoba.ca ${ }^{1}$ Section of Nephrology, Department of Internal Medicine, Health Sciences Centre, University of Manitoba, Room GE644, 820 Sherbrook St, Winnipeg, Manitoba R3A 1R9, Canada

${ }^{3}$ Department of Community Health Sciences, University of Manitoba,

S113-750 Bannatyne Ave, Winnipeg, Manitoba R3E OW3, Canada

Full list of author information is available at the end of the article
}

which appears 5-10 years prior to the onset of overt proteinuria. Proteinuria is a sign of more advanced renal disease and is a precursor to renal failure [11]. Importantly, albuminuria is a strong and independent predictor of cardiovascular and all cause mortality [12]. Additionally, the impact of renal disease on health care costs and quality of life for patients and their caregivers is substantial [13-16]. Blood pressure and glucose control among those with diabetes and/or chronic kidney disease, with either medication and/or lifestyle changes have shown to be effective in preventing progression to advanced renal disease [17-19]. Therefore screening for albuminuria in
C Biomed Central

(c) 2012 Zacharias et al; licensee BioMed Central Ltd. This is an Open Access article distributed under the terms of the Creative Commons Attribution License (http://creativecommons.org/licenses/by/2.0), which permits unrestricted use, distribution, and reproduction in any medium, provided the original work is properly cited. 
high risk populations may be one component of an effective community-based renal disease prevention strategy.

While the excess burden of diabetes among First Nations populations compared to the general Canadian population is well established [20], research on diabetesrelated kidney disease among Canadian First Nations populations is more limited. A retrospective populationbased study from Saskatchewan for the years 1981-90 revealed that among those with diabetes, the rate of ESRD in First Nation people was 7 times greater than among non-First Nation people [2]. The prevalence of microalbuminuria among a sample of 601 First Nation residents in northern Saskatchewan was 24\% among those with diabetes, and 9\% among those without [21]. Non-diabetic diseases, such as glomerulonephritis, that can lead to ESRD and which can present with albuminuria and hematuria are also significantly increased in First Nation people [3]. According to the Canadian Diabetes Association Clinical Practice Guidelines, First Nations adults with at least one risk factor should be screened for diabetes every 1-2 years and those with type 2 diabetes should be screened for albuminuria at diagnosis and annually thereafter [22]. Despite these recommendations and the increased burden of diabetic and non-diabetic renal disease, few population-based screening studies for albuminuria among Canadian First Nation populations have been performed. The study community reported in this article has a high prevalence of ESRD (5\%), diabetes (29\%) and impaired fasting glucose (7\%) [23]. Thus, the community is at high risk for diabetic renal complications. Therefore the purpose of this paper is to determine the prevalence and determinants of albuminuria in a Canadian First Nation population, and to begin planning for secondary prevention strategies.

\section{Methods}

The data for this paper are from a previously described larger screening study for diabetes and diabetes complications [23] conducted in 2003 among adult members of the Sandy Bay First Nation, located about $200 \mathrm{~km}$ northwest of Winnipeg, Manitoba, Canada, with year round road access. Its population in December 2001 was 2,968, of which $52 \%$ were under the age of 18 . Inclusion criteria were: non-pregnant, community member, and 18 years and older. A total of 483 community members participated; $36 \%$ of all eligible adults $(n=1356)$. That is, there were 1356 eligible adults in the community, according to the inclusion criteria, and 483 chose to participate. Estimates of albuminuria were obtained on the 468 participants who had completed all components of the study, which included anthropometrics (height, weight, and waist and hip circumferences); a demographic and health status questionnaire; fasting blood samples for glucose, A1c,and lipids; and random urine sample. Although albuminuria is not the best clinical tool to identify kidney disease, for an epidemiological screening study, albuminuria is an excellent predictor for ESRD, CVD, and all-cause mortality [12]. This study was approved by the Health Research Ethics Board at the University of Manitoba.

\section{Measures}

Urine albumin:creatinine ratio (ACR) was determined using the Bayer ${ }^{\circledR}$ DCA $2000^{m}$ Point-of-Care Analyzer, which is highly accurate and reproducible [24,25]. Each urine sample was first tested by a Multistix Reagent strips for presence of protein, and blood. Participants' whose samples tested "trace or more" for blood or $\geq 1 \mathrm{~g} / \mathrm{L}$ protein were requested to return on another day. Samples negative for blood and protein were loaded into the DCA $2000^{\circ \prime}$. Microalbuminuria was defined as no positive dipstick reading for protein and at least one test with ACR $>2.8 \mathrm{mg} / \mathrm{mmol}$ for women and $>2.0 \mathrm{mg} / \mathrm{mmol}$ for men. Individuals with dipstick positive proteinuria $(>1 \mathrm{~g} / \mathrm{L})$ or those with ACR in the macroalbuminuria of proteinuria range $(\geq 30 \mathrm{mg} / \mathrm{mmol})$ on at least one sample were considered to have proteinuria. A maximum of three samples were obtained.

Venous samples for glucose, were drawn after an overnight 12-hour fast. Participants with fasting glucose values $\geq 5.8 \mathrm{mmol} / \mathrm{L}$ were requested to return for a second sample; the average of the two samples was used in analysis. Diabetes was defined as a fasting blood glucose $\geq 7.0 \mathrm{mmol} / \mathrm{L}$. Impaired fasting glucose was defined as fasting blood glucose of 6.1-6.9 mmol/L, as per the Canadian Diabetes Association [26]. Samples were analyzed at the Clinical Chemistry Lab at the Health Sciences Centre, Winnipeg, Manitoba.

Blood pressure was measured on site by a registered nurse or a trained research assistant, working under the supervision of the registered nurse. The average of two readings was used. Hypertension was defined as a blood pressure $>140 / 90 \mathrm{~mm} \mathrm{Hg}$ for those without diabetes, $\geq 130$ / $80 \mathrm{~mm} \mathrm{Hg}$ for those with diabetes and/or albuminuria, according to the American Diabetes Association [27,28], or a previous diagnosis treated with medication. Anthropometric measures including height, weight, and waist and hip circumferences were completed using standard techniques [29]. Current and past smoking status and number of cigarettes smoked per day were determined using a standardized questionnaire. Pack years was calculated as number of packs per day ( 1 pack $=20$ cigarettes) multiplied by number of years smoked. Standard demographic information and diabetes history were derived via questionnaire. Awareness of disease states by participant, such as diabetes, hypertension and kidney disease, was asked by a simple direct question in similar fashion to the NHANES III study cohort [30]. 


\section{Statistical analyses}

Data are presented as mean (standard deviation) for continuous variables, median (range) for continuous variables that do not follow a normal distribution, and as $\mathrm{n}$ (percent) for categorical variables. Demographic, anthropometric and health characteristics were compared using $t$-tests for normally distributed continuous variables, $\chi^{2}$ tests for categorical variables and Mann-Whitney $U$ non-parametric tests for non-normally distributed continuous variables. Univariate and multiple logistic regression (backwards stepwise) were used to determine associations with albuminuria. Continuous variables were also explored as categorical variables to determine appropriateness of assumptions of linearity. Those variables that were found to be significant in univariate analysis, as well as independent of age, were included as potential variables in the backwards stepwise logistic regression model. Tests were two-tailed with $\mathrm{p}<0.05$ considered significant. Statistical analyses were performed using SPSS (version 16).

\section{Results}

The study sample was representative of the larger community for age, sex, education and employment status [23]. That is, the sample had similar proportions of the previously listed characteristics as the study population. Nine subjects were ineligible due to incomplete data and 6 were excluded from the albuminuria analysis due to persistent hematuria, leaving 468 subjects for albuminuria analysis. Participants with persistent hematuria were excluded due to the inability to obtain an ACR and we could not determine the cause of the hematuria. These individuals were referred for clinical evaluation. However, most individuals whose first test was positive for hematuria were found not to be hematuric on subsequent tests and were included in analysis. The majority of these participants were women who were tested close to their menstrual period.

Demographic and health risk characteristics of the study population are described in Table 1. Both sexes were equally represented. The population was young and the mean age was similar for men and women (37 for men; 38 for women). Less than half the study sample had completed grade 9. The study population had high rates of cardiovascular risk factors; three-quarters of participants were current smokers, $43 \%$ had hypertension, $35 \%$ had diabetes or prediabetes and obesity was highly prevalent.

Twenty-five percent of the sample returned for at least a second random urine test (Table 2). However, of those who had abnormal samples (ie. hematuria or proteinuria) on their first test, $79 \%$ returned for a second or third test. Albuminuria was present in $95 / 468$ or $20 \%$ of participants. Twenty-five participants $(5 \%)$ had proteinuria and $70(15 \%)$ had microalbuminuria. In univariate
Table 1 Demographic and health risk characteristics of the study sample

\begin{tabular}{|c|c|}
\hline Characteristic & Value $^{1}$ \\
\hline Age (years) & $38(12)^{a}$ \\
\hline Female & $253(52)$ \\
\hline Grade 9 or higher & $220(47)$ \\
\hline Employed & $137(29)$ \\
\hline Ever smoked & $391(82)$ \\
\hline Current smoker & $349(74)$ \\
\hline Hypertension $^{2}$ & $201(43)$ \\
\hline Body Mass Index $\left(\mathrm{kg} / \mathrm{m}^{2}\right)$ & $31.5(7)^{a}$ \\
\hline Diabetes $^{3}$ & $140(29)$ \\
\hline Impaired fasting glucose $e^{4}$ & $30(6.2)$ \\
\hline Average fasting blood glucose (mmol/L) & $5.4(3.4,20.6)^{\mathrm{b}}$ \\
\hline Albuminuria ${ }^{5}$ & $95(20)$ \\
\hline Aware $^{6}$ of diabetes & 107(76) \\
\hline Aware of hypertension & $127(63)$ \\
\hline Aware of kidney disease & $5(5)$ \\
\hline
\end{tabular}

${ }^{1}$ Data are reported as $\mathrm{n}$ (percentage), mean (standard deviation) ${ }^{\mathrm{a}}$ or median (range) $^{\mathrm{b}}$.

${ }^{2}$ Hypertension is defined as a blood pressure $>140 / 90 \mathrm{~mm} \mathrm{Hg}$ for those without diabetes, $\geq 130 / 80 \mathrm{~mm} \mathrm{Hg}$ for those with diabetes, or a previous diagnosis with medications.

${ }^{3}$ Diabetes is defined as fasting glucose $\geq 7.0 \mathrm{mmol} / \mathrm{L}$ or previous diagnosis. ${ }^{4} \mathrm{Impaired}$ fasting glucose is fasting glucose between $6.1 \mathrm{mmol} / \mathrm{L}$ and $6.9 \mathrm{mmol} / \mathrm{L}$ with no previous diagnosis of diabetes.

${ }^{5}$ Albuminuria is albumin:creatinine ratio $>2.8 \mathrm{mg} / \mathrm{mmol}$ for women and $>2.0 \mathrm{mg} /$ mmol for men.

${ }^{6}$ Awareness of disease states refers to participant awareness.

analysis [OR (95\% CI) p-value], age [1.039 $(1.008,1.072)$ $\mathrm{p}=0.014]$, diabetes [11.474 $(4.209,31.279) \mathrm{p}<0.001$, systolic blood pressure [1.039 $(1.019,1.061) \mathrm{p}<0.001]$, diastolic blood pressure $[1.051(1.018,1.086) \mathrm{p}=0.002]$, fasting glucose $[1.257(1.155,1.367) \mathrm{p}<0.001]$ and hypertension $[4.390(1.709,11.277) \mathrm{p}=0.002]$ were associated with proteinuria. There was a non-significant trend for lower odds of proteinuria among females [0.428 (0.181, 1.012) $\mathrm{p}=0.053]$. BMI, ever smoker, and years diagnosed with diabetes were not associated with proteinuria. For all other analysis, those with proteinuria and microalbuminuria were combined for analysis due to small numbers and equivalence on the following characteristics: age, sex, smoking status and mean years smoked. However, the proportion of those with diabetes was greater among the proteinuria group compared to the microalbuminuria group. Eighty percent (20/25) of those with proteinuria had diabetes.

Participants with and without albuminuria are compared in Table 3. Those with albuminuria were older $(\mathrm{p}<0.001)$ and albuminuria prevalence progressively increased with age (Figure 1). Men were more likely to have albuminuria than women $(\mathrm{p}=0.01)$. Interestingly, those with 
Table 2 Albuminuria category by number of tests done

\begin{tabular}{|c|c|c|c|c|}
\hline \multirow{2}{*}{$\begin{array}{l}\text { Number of urine } \\
\text { tests done }\end{array}$} & \multicolumn{3}{|c|}{ Albuminuria Category } & \multirow[b]{2}{*}{ Totals } \\
\hline & Normo-albuminuria & Microalbuminuria $^{a}$ & Proteinuria $^{b}$ & \\
\hline 1 & 321 (69\%) & $22(4.7 \%)$ & $6(1.3 \%)$ & $349(75 \%)$ \\
\hline 2 & $48(10 \%)$ & $39(8.2 \%)$ & $14(3 \%)$ & $101(22 \%)$ \\
\hline 3 & $4(0.8 \%)$ & $9(1.9 \%)$ & $5(1.1 \%)$ & $18(3.8 \%)$ \\
\hline Totals & $373(80 \%)$ & $70(15 \%)$ & $25(5.3 \%)$ & 468 \\
\hline
\end{tabular}

albuminuria were less likely to report ever having smoked $(p=0.007)$. However, neither years of smoking nor packyears smoked were significantly different between groups. Participants with albuminuria were more likely to be hypertensive by any measure. Seventy percent $(70 \%)$ of those with albuminuria had hypertension compared with $36 \%$ of those without albuminuria $(\mathrm{p}<0.0001)$. In this

Table 3 Comparison of those with and without albuminuria

\begin{tabular}{|c|c|c|c|}
\hline Characteristic & $\begin{array}{l}\text { Albuminuria } \\
\qquad(n=95)\end{array}$ & $\begin{array}{l}\text { No albuminuria } \\
(n=373)\end{array}$ & $P$ \\
\hline Age (years) & $42(13)$ & $36(12)$ & $<0.001$ \\
\hline \multicolumn{4}{|l|}{ Sex } \\
\hline Female & $38(40.4)$ & $201(54.0)$ & 0.02 \\
\hline Male & $56(59.6)$ & $171(46.0)$ & \\
\hline Ever a smoker & 67 (72.0) & 311 (84.1) & 0.007 \\
\hline Years smoked ${ }^{a}$ & $12(0,50)$ & $10(0,50)$ & 0.941 \\
\hline Pack years smoked ${ }^{a}$ & $1.5(0,88)$ & $2.6(0,74)$ & 0.291 \\
\hline $\begin{array}{l}\text { Previous hypertension } \\
\text { diagnosis }\end{array}$ & $38(42.7)$ & 78 (21.9) & $<0.001$ \\
\hline Hypertension $^{1}$ & $64(68.8)$ & $131(35.7)$ & $<0.001$ \\
\hline Systolic BP $(\mathrm{mm} \mathrm{Hg})^{b}$ & 134 (19) & $125(15)$ & $<0.001$ \\
\hline Diastolic BP $(\mathrm{mm} \mathrm{Hg})^{b}$ & $80(12)$ & $76(10)$ & $<0.001$ \\
\hline $\begin{array}{l}\text { Blood pressure } \geq 130 \text { / } \\
80 \mathrm{~mm} \mathrm{Hg}^{2}\end{array}$ & $62(66.0)$ & $189(51.2)$ & 0.01 \\
\hline $\begin{array}{l}\text { Body Mass Index } \\
\left(\mathrm{kg} / \mathrm{m}^{2}\right)^{\mathrm{b}}\end{array}$ & $32.9(5.79)$ & $31.1(7.25)$ & 0.03 \\
\hline Diabetes $^{3}$ & $57(60.6)$ & $77(20.7)$ & $<0.001$ \\
\hline Dysglycemia $^{4}$ & $64(68.1)$ & $97(26.1)$ & $<0.001$ \\
\hline $\begin{array}{l}\text { Fasting glucose } \\
(\mathrm{mmol} / \mathrm{L})^{\mathrm{b}}\end{array}$ & 9.7 (4.6) & $6.2(2.6)$ & $<0.001$ \\
\hline Hematuria $^{5}$ & 8.4 & 2.9 & 0.001 \\
\hline
\end{tabular}

Data are reported as $\mathrm{n}$ (percentage), mean (standard deviation) ${ }^{\mathrm{a}}$, median (range) ${ }^{\mathrm{b}}$.

${ }^{1}$ Hypertension is defined as a previous diagnosis of hypertension or blood pressure $\geq 140 / 90 \mathrm{~mm} \mathrm{Hg}$.

${ }^{2}$ Blood pressure $\geq 130 / 80 \mathrm{~mm} \mathrm{Hg}$ includes only participants with previous diagnosis of diabetes or hypertension.

${ }^{3}$ Diabetes is defined as on oral hypoglycemics, self declared diabetes or has a fasting glucose $\geq 7.0 \mathrm{mmol} / \mathrm{L}$.

${ }^{4}$ Dysglycemia is defined as previous diagnosis of diabetes or a fasting plasma glucose $\geq 6.1 \mathrm{mmol} / \mathrm{L}$.

${ }^{5}$ Hematuria was a positive dipstick for hemoglobin. regard, mean blood pressures were significantly higher in the group with albuminuria compared to those without. Target blood pressure in those with albuminuria is generally recommended to be $<130 / 80 \mathrm{~mm} \mathrm{Hg}$, however, this was achieved in only $34 \%$ of those with albuminuria.

Participants with albuminuria were significantly heavier and had a higher BMI (Figure 2). This increased weight and BMI may be related to the greater proportion of participants in the albuminuric group with diabetes and impaired fasting glucose. Fasting glucose was also higher among those with albuminuria compared to those without $(\mathrm{p}<0.001)$. While almost $60 \%$ of those with any degree of albuminuria had diabetes, $42 \%$ of those with diabetes were albuminuric.

Odds ratios and 95\% CI are listed in Table 4 for both univariate and multivariate logistic regression. Backwards stepwise multivariate logistic regression was performed. Univariate analysis indicated the odds of having microalbuminuria increased $4 \%$ for each year increase in age. However, age was not significant in the final multivariate model. When both fasting glucose and years of diabetes were removed from the model and age was included, age became significant suggesting high multicolinearity between the diabetes and age (model not shown). Females were less likely to have microalbuminuria than males, which remained significant in the multivariate model. Smokers were less likely to have albuminuria than nonsmokers and while smoking appeared protective in univariate analysis, it did not achieve significance in the multivariate model.

Those with diabetes were seven times more likely to have albuminuria than those without diabetes. In addition, for each $\mathrm{mmol} / \mathrm{L}$ increase in average fasting glucose, albuminuria increased by $27 \%$ in the univariate model, and $20 \%$ when controlling for sex, years diagnosed with diabetes, systolic blood pressure and BMI. Length of time with diabetes was also a significant predictor of albuminuria and confirms the natural history of diabetic nephropathy. Systolic blood pressure was independently associated with albuminuria in the multivariate model and risk of albuminuria increased by $2 \%$ for every $\mathrm{mm} \mathrm{Hg}$ increase in systolic blood pressure. Lastly, weight and BMI were both significant alone, but BMI 


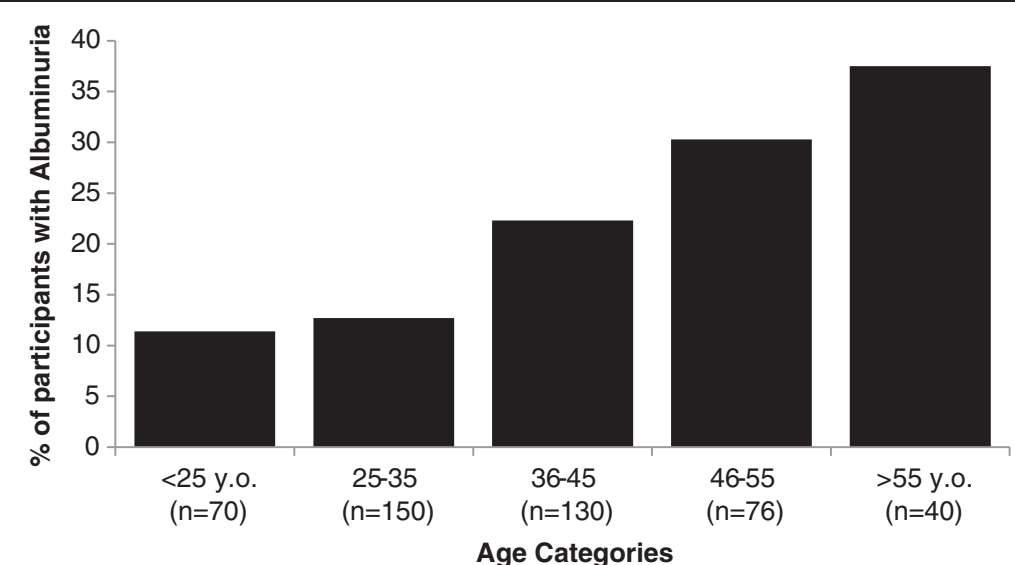

Figure 1 Percent albuminuria by age categories. There is a significant linear association between age group and proportion of those with albuminuria $(p<0.001)$. ' $n$ ' refers to the total number of participants in respective age category.

was an independent predictor of albuminuria in the multivariate analysis, after accounting for average fasting glucose, gender, years diagnosed with diabetes mellitus and systolic blood pressure [1.042 (1.001, 1.085), $\mathrm{p}=0.04]$.

In contrast to participants with diabetes and hypertension, very few with albuminuria were aware of their condition. Participant awareness of kidney disease increased with severity such that $17 \%$ of those with proteinuria were aware of kidney disease while awareness kidney disease in those with microalbuminuria was only $1 \%$ (Table 1 ).

\section{Discussion}

High prevalence of diabetes and renal complications of diabetes (ESRD) have been previously described among Canadian First Nations people [1,2,31-33]. Significant rates of renal complications (ESRD) among non-diabetic First Nations people are also seen [3,34]. Microalbuminuria is well recognized as a significant precursor to either diabetic or non-diabetic renal disease, and has been described in both those with and without diabetes. In the current population-based study, albuminuria rates of $20 \%$ among the total population were as high as among other high-risk populations such as the Pima in the southwestern United States $[4,7,35]$. Among those with diabetes in our study, $42 \%$ had albuminuria, which is substantially greater than the prevalence among the general US population (28.8\%) as described in the NHANES III study [36], and the $24 \%$ estimated in a Canadian First Nation population-based study in Saskatchewan [21]. The present study prevalence is comparable to the American Pima and Zuni populations in which $47 \%$ and $52 \%$ of the diabetic population, respectively, had albuminuria $[7,15]$.

The current study found female gender protective for albuminuria, independent of fasting glucose, years with

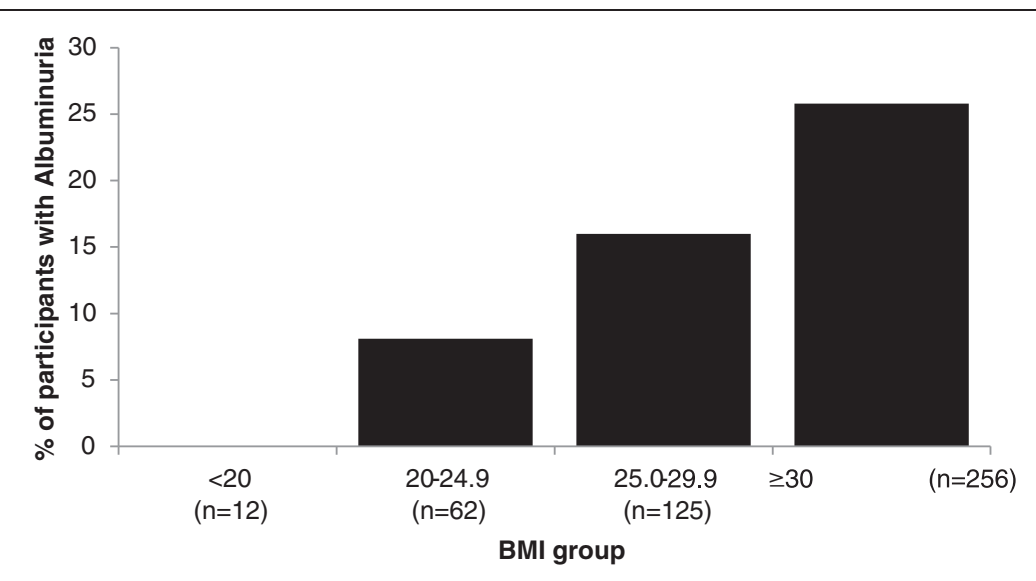

Figure 2 Percent albuminuria by BMI categories. There is a significant linear association between BMI category and proportion of those with albuminuria $(p<0.001)$. ' $n$ ' refers to the total number of participants in respective age category. 
Table 4 Univariate and multivariate logistic regression with albuminuria as an outcome

\begin{tabular}{|c|c|c|}
\hline & Odds ratio $(95 \% \mathrm{Cl})$ & $\mathrm{p}$-value \\
\hline \multicolumn{3}{|l|}{ Univariate logistic regression } \\
\hline Age, years & $1.040(1.021,1.059)$ & $<0.0001$ \\
\hline \multicolumn{3}{|l|}{ Sex } \\
\hline Male & 1 & \\
\hline Female & $0.560(0.354,0.885)$ & 0.01 \\
\hline \multicolumn{3}{|l|}{ Ever smoked } \\
\hline No & 1 & \\
\hline Yes & $0.485(0.285,0.825)$ & 0.01 \\
\hline \multicolumn{3}{|l|}{ Diabetes mellitus } \\
\hline No & 1 & \\
\hline Yes & $7.718(4.412,13.5)$ & $<0.001$ \\
\hline Average fasting glucose, $\mathrm{mmol} / \mathrm{L}$ & $1.27(1.192,1.352)$ & $<0.001$ \\
\hline Years diagnosed with DM & $1.127(1.078,1.179)$ & $<0.001$ \\
\hline \multicolumn{3}{|l|}{ Hypertension } \\
\hline No & 1 & \\
\hline Yes & $2.860(1.790,4.560)$ & $<0.001$ \\
\hline Systolic blood pressure, $\mathrm{mmHg}$ & $1.032(1.019,1.046)$ & $<0.001$ \\
\hline Diastolic blood pressure, $\mathrm{mmHg}$ & $1.034(1.013,1.055)$ & $<0.005$ \\
\hline BMl & $1.036(1.004,1.070)$ & 0.03 \\
\hline \multicolumn{3}{|l|}{ Hematuria } \\
\hline No & 1 & \\
\hline Yes & $3.079(1.201,7.877)$ & 0.02 \\
\hline \multicolumn{3}{|l|}{ Multivariate logistic regression } \\
\hline \multicolumn{3}{|l|}{ Sex } \\
\hline Male & 1 & \\
\hline Female & $0.407(0.230,0.771)$ & 0.002 \\
\hline Average fasting glucose, $\mathrm{mmol} / \mathrm{L}$ & $1.200(1.115,1.29)$ & $<0.001$ \\
\hline Years diagnosed with DM & $1.057(1.004,1.113)$ & 0.03 \\
\hline Systolic blood pressure, $\mathrm{mmHg}$ & $1.020(1.005,1.035)$ & 0.01 \\
\hline BMl & $1.042(1.001,1.085)$ & 0.04 \\
\hline
\end{tabular}

DM, diabetes mellitus; BMI, body mass index.

diabetes, systolic blood pressure or BMI. This association was also found in the Strong Heart Study [37]. This contrasts with the NHANES III and Pima Indian non-diabetic data, in which women had significantly more albuminuria than men $[7,36]$. The NHANES III study, however, did not use the lower cut-off for ACR in males, as did the current study. A different ACR cut-off due to higher excreted creatinine in males has been supported by many investigators and is supported by the Canadian Diabetes Association Clinical Practice Guidelines [26,3840], and may account for the differences between the NHANES and Pima Indian non-diabetic data and the current study. Furthermore, in the Pima diabetic population and the Zuni Indian population studies, no sex differences were seen $[4,7,35]$. Mortality rates among men with albuminuria tend to be higher than in women [41], and therefore the increased albuminuria among men in our study is concerning.

BMI was also independently related to increased prevalence of albuminuria in the study sample. Although increased BMI has been described as a risk factor for albuminuria and proteinuria [42] and high BMI is an issue among those of First Nations ancestry [43-45], to our knowledge, BMI has not been previously described as an independent risk factor for microalbuminuria in the Canadian First Nations population.

While age has been found to be significantly associated with albuminuria [36], age was not included in our final multivariate model, likely due to high multicolinearity with duration of diabetes and diabetes itself. However, the average age of those with albuminuria increased by glycemic status (i.e., non-diabetes, IFG and diabetes). While by no means confirmatory, this suggests a possible difference in lead time. As albuminuria is a risk factor for diabetes [46], those younger individuals with dysglycemia and even without diabetes, may develop diabetes as they age.

Participant awareness of kidney disease in a First Nation community is reported here for the first time. Awareness of kidney disease within the study population was low compared to other disease states such as diabetes and hypertension. Awareness of kidney disease was also lower than that found among the general U.S. population where $24 \%$ of participants reported being aware of their kidney disease [29]. Disease awareness is related to many factors at both the individual and systems levels. At the individual level, reported awareness of disease can be limited by patient understanding and denial; that is, although care providers may inform patients of their illness, patients may not integrate that information. Another factor affecting awareness is lack of screening or diagnostic testing on the part of health care providers, thereby preventing detection. At the systems level, access to physicians on the part of patients and suitable practice environments for physicians (i.e., access to and remuneration for diagnostic testing) can either enable or act as barriers to preventive practice. Factors influencing poor disease awareness among our study population could not be determined. Thus, further research is required to address the lower than anticipated awareness in this high-risk population.

The study is subject to limitations. The sample size is limited and was not randomly selected from the eligible population. However, our sample was representative of the eligible study population on demographic factors (i.e., age, sex, employment, education) and, as previously reported [23], was not over-represented by the ill or infirmed. In fact, only $38 \%$ of those known to have diabetes at the start of the study were participants. In addition, only three out 
of 10 individuals with previous amputations participated in the study, and none of the 15 individuals with ESRD participated. Therefore, we are confident that our sample represents the larger community. However, the results may not be generalizable beyond the study population because we are not able to determine if the study population is representative of First Nations communities across Canada. Furthermore, the lack of availability of serum creatinine to further indicate severity of renal dysfunction is also a limitation. Lastly, those participants that had a normal ACR did not complete repeat testing.

\section{Conclusions}

Albuminuria is an important complication of diabetes and a risk factor for ESRD and cardiovascular disease. Identification of relevant risk factors is therefore an important activity that can assist in the development of targeted prevention efforts. Interestingly, we found the presence of significant numbers of people with microalbuminuria and hematuria without other risk factors, confirming the presence of non-diabetic renal disease. Further investigations should be focused on this group; first to help ascertain the cause of their hematuria or albuminuria, and second to intervene appropriately. Lack of awareness of early renal disease among study participants is a concern and efforts to understand the phenomenon and improve awareness will be undertaken in partnership with the community. Ongoing longitudinal follow-up of the individuals in this study would further our understanding of the significance of individual health determinants. In addition, further follow-up would give important information about the natural history of albuminuria in this population. The response to treatment and community intervention strategies could also be assessed.

\section{Abbreviations \\ ACE: Angiotensin-converting enzyme; ACR: Albumin-creatinine ratio; ARB: Angiotensin receptor blocker; BMI: Body mass index; ESRD: End-stage renal disease.}

\section{Competing interests}

The authors declare that they have no competing interests.

\section{Acknowledgements and funding}

We would like to thank the Canadian Institute for Health Research (CIHR -TKY) and the Manitoba Health Research Council (SGB) for their funding. NDR is funded by a CIHR Frederick Banting and Charles Best Canada Graduate Scholarship. Finally, we gratefully acknowledge the study community, staff and leadership for their participation and on-going commitment.

\section{Author details}

${ }^{1}$ Section of Nephrology, Department of Internal Medicine, Health Sciences Centre, University of Manitoba, Room GE644, 820 Sherbrook St, Winnipeg, Manitoba R3A 1R9, Canada. ${ }^{2}$ Dalla Lana School of Public Health, University of Toronto, 155 College St, Toronto, Ontario M5T 3M7, Canada. ${ }^{3}$ Department of Community Health Sciences, University of Manitoba,

S113-750 Bannatyne Ave, Winnipeg, Manitoba R3E 0W3, Canada. ${ }^{4}$ Sandy Bay Ojibway First Nation, Sandy Bay Health Centre, Box 110, Marius, Manitoba ROH OTO, Canada.

\section{Authors' contributions}

JZ conducted data analysis, interpretation, and preparation of the manuscript. KY is the principal investigator and was involved in the conception and design of the study, analysis and has reviewed this manuscript for intellectual content. NDR assisted in data analysis and preparation of the manuscript for publication. JR is the Director of the health centre in the community and was involved in the conception and design of the study. SB contributed to the conception and design of the study as well as acquisition of the data, analysis and preparation of the manuscript. All authors read and approved the final manuscript.

Received: 12 August 2011 Accepted: 20 April 2012

Published: 20 April 2012

\section{References}

1. Young TK, Kaufert JM, McKenzie JK, Hawkins A, O'Neil J: Excessive burden of end-stage renal disease among Canadian Indians: a national survey. Am J Public Health 1989, 79:756-758.

2. Dyck RF, Tan L: Rates and outcome of diabetic end-stage renal disease among registered native people in Saskatchewan. CMAJ 1994, 150:203-208.

3. Dyck RF, Tan L: Non-diabetic end-stage renal disease among Saskatchewan aboriginal people. Clin Invest Med 1998, 21:33-38.

4. Stidley CA, Shah VO, Scavini M, Narva AS, Kessler D, Bobelu A, et al: The Zuni kidney project: a collaborative approach to an epidemic of kidney disease. J Am Soc Nephrol 2003, 14:S139-S143.

5. Sosenko JM, Hu D, Welty T, Howard BV, Lee E, Robbins DC: Albuminuria in recent-onset type 2 diabetes: the Strong Heart Study. Diabetes Care 2002, 25:1078-1084.

6. Hirata-Dulas CA, Rith-Najarian SJ, Mclntyre MC, Ross C, Dahl DC, Keane WF et al: Risk factors for nephropathy and cardiovascular disease in diabetic Northern Minnesota American Indians. Clin Nephrol 1996, 46:92-98.

7. Nelson RG, Kunzelman CL, Pettitt DJ, Saad MF, Bennett PH, Knowler WC: Albuminuria in type 2 (non-insulin-dependent) diabetes mellitus and impaired glucose tolerance in Pima Indians. Diabetologia 1989, 32:870-876.

8. Nelson RG, Knowler WC, Pettitt DJ, Hanson RL, Bennett PH: Incidence and determinants of elevated urinary albumin excretion in Pima Indians with NIDDM. Diabetes Care 1995, 18:182-187.

9. Weir MR: Albuminuria predicting outcome in diabetes: incidence of microalbuminuria in Asia-Pacific Rim. Kidney Int 2004, 66:S38-S39. Suppl.

10. Gross JL, de Azevedo MJ, Silveiro SP, Canani LH, Caramori ML, Zelmanovitz T: Diabetic nephropathy: diagnosis, prevention, and treatment. Diabetes Care 2005, 28:164-176.

11. Mogensen CE: Management of early nephropathy in diabetic patients. Annu Rev Med 1995, 46:79-93.

12. Chronic Kidney Disease Prognosis Consortium: Association of estimated glomerular filtration rate and albuminuria with all-cause and cardiovascular mortality in general population cohorts: a collaborative meta-analysis. Lancet 2010, 375:2073-2081.

13. Belasco AG, Sesso R: Burden and quality of life for caregivers for hemodialysis patients. Am J Kidney Dis 2002, 39:805-812.

14. Merkus MP, Jager KJ, Dekker FW, Boeschoten EW, Stevens P, Krediet RT, et al: Quality of life in patients on chronic dialysis: self-assessment 3 months after the start of treatment. Am J Kidney Dis 1997, 29:584-592.

15. Moist LM, Bragg-Gresham JL, Pisoni RL, Saran R, Akiba T, Jacobson SH, et al: Travel time to dialysis as a predictor of health-related quality of life, adherence and mortality: the Dialysis Outcomes and Practice Patterns Study (DOPPS). Am J Kidney Dis 2008, 51:641-650.

16. Zelmer JL: The economic burden of end-stage renal disease in Canada. Kidney Int 2007, 72:1122-1129.

17. Tobe SW, Pylypchuk G, Wentworth J, Kiss A, Szalai JP, Perkins N, et al: Effect of nurse-directed hypertension treatment among First Nations people with existing hypertension and diabetes mellitus: the Diabetes Risk-Evaluation and Microalbuminuria (DREAM 3) randomized controlled trial. CMAJ 2006, 174:1267-1271.

18. Kshirsager AV, Joy MS, Hogan HL, Falk RJ, Colindres RE: Effect of Ace inhibitors in Diabetic and Non-Diabetic Chronic Renal Disease: a Systematic Overview of Randomized Placebo-Controlled Trials. Am J Kidney Dis 2000, 35:695-707.

19. Mann JF, Gerstein HC, Yi QL, Lonn EM, Hoogwerf BJ, Rashkow A, et al: Development of renal disease in people at high cardiovascular risk: 
results of the HOPE randomized study. J Am Soc Nephrol 2003, 14:641-647.

20. Young TK, Reading J, Elias B, O'Neil JD: Type 2 diabetes mellitus in Canada's first nations: status of an epidemic in progress. CMAJ 2000 163:561-566.

21. Pylypchuk G, Vincent L, Wentworth J, Kiss A, Perkins N, Hartman S, et al: Diabetes Risk Evaluation and Microalbuminuria (DREAM) studies: ten years of participatory research with a First Nation's home and Community Model for type 2 Diabetes Care in Northern Saskatchewan. Int J of Circumpolar Health 2008, 67:190-202.

22. McFarlane P, Culleton B: Canadian Diabetes Associate Clinical Practice Guidelines Expert Committee: Chonic Kidney Disease in Diabetes. Can J Diabetes 2008, 32:S126-S133.

23. Bruce SG, Young TK: Prevalence and risk factors for neuropathy in a Canadian First Nation community. Diabetes Care 2008, 31:1837-1841.

24. Collins AC, Vincent J, Newall RG, Mitchell KM, Viberti GC: An aid to the early detection and management of diabetic nephropathy: assessment of a new point of care microalbuminuria system in the diabetic clinic. Diabet Med 2001, 18:928-932.

25. Parsons M, Newman DJ, Pugia M, Newall RG, Price CP: Performance of a reagent strip device for quantitation of the urine albumin: creatinine ratio in a point of care setting. Clin Nephrol 1999, 51:220-227.

26. Canadian Diabetes Association: Clinical practice guidelines for the prevention and management of Diabetes in Canada. Can J Diabetes 2008, 32(Suppl 1):S126-S133.

27. American Diabetes Association: Executive summary: standards of medical care in diabetes -2011. Diabetes Care 2011, 34:S4-S10

28. Chobanian AV, Bakris GL, Black HR, Cushman WC, Green LA, Izzo JL Jr, et al: The Seventh Report of the Joint National Committee on Prevention, Detection, Evaluation, and Treatment of High Blood Pressure: the JNC 7 report. JAMA 2003, 289:2560-2572.

29. The Canadian Physical Activity, Fitness and Lifestyle appraisal. CSEP, 1996.

30. Coresh J, Byrd-Holt D, Astor BC, Briggs JP, Eggers PW, Lacher DA, et al: Chronic kidney disease awareness, prevalence, and trends among U.S. adults, 1999 to 2000. J Am Soc Nephrol 2005, 16:180-188.

31. Brassard P, Robinson E, Dumont C: Descriptive epidemiology of non-insulin-dependent diabetes mellitus in the James Bay Cree population of Quebec, Canada. Arctic Med Res 1993, 52:47-54.

32. Morrison N, Dooley J: The Sioux Lookout Diabetes Program: diabetes prevention and management in northwestern Ontario. Int I Circumpolar Health 1998, 57:364-369.

33. Young TK, Szathmary EJ, Evers S, Wheatley B: Geographical distribution of diabetes among the native population of Canada: a national survey. Soc Sci Med 1990, 31:129-139.

34. Rigatto $C$, Bernstein $\mathrm{K}$ : Abstract: trends in incidence and prevalence of diabetic (D) and non-diabetic (ND) end-stage renal disease (ESRD) in First Nations (FN) and non-First Nations adults in Manitoba: 1997 to 2003. J Am Soc Nephrol 2005, 16:295A.

35. Shah VO, Scavini M, Stidley CA, Tentori F, Welty TK, MacCluer JW, et al: Epidemic of diabetic and nondiabetic renal disease among the Zuni Indians: the Zuni Kidney Project. J Am Soc Nephrol 2003, 14:1320-1329.

36. Jones CA, Francis ME, Eberhardt MS, Chavers B, Coresh J, Engelgau M, et al: Microalbuminuria in the US population: third National Health and Nutrition Examination Survey. Am J Kidney Dis 2002, 39:445-459.

37. Robbins DC, Knowler WC, Lee ET, Yeh J, Go OT, Welty T, et al: Regional differences in albuminuria among American Indians: an epidemic of renal disease. Kidney Int 1996, 49:557-563.

38. Houlihan CA, Tsalamandris C, Akdeniz A, Jerums G: Albumin to creatinine ratio: a screening test with limitations. Am J Kidney Dis 2002, 39: 1183-1189.

39. Mogensen CE, Vestbo E, Poulsen PL, Christiansen C, Damsgaard EM, Eiskjaer $\mathrm{H}$, et al: Microalbuminuria and potential confounders. A review and some observations on variability of urinary albumin excretion. Diabetes Care 1995, 18:572-581.

40. Warram JH, Gearin G, Laffel L, Krolewski AS: Effect of duration of type I diabetes on the prevalence of stages of diabetic nephropathy defined by urinary albumin/creatinine ratio. J Am Soc Nephrol 1996, 7:930-937.

41. Romundstad S, Holmen J, Hallan H, Kvenild K, Ellekjaer H: Microalbuminuria and all-cause mortality in treated hypertensive individuals: does sex matter? The Nord-Trondelag Health Study (HUNT), Norway. Circulation 2003, 108:2783-2789.
42. Afghahi H, Cederholm J, Eliasson B, Zethelius B, Gudbjrnsdottir S, Hadimeri $H$, Svensson MK: Risk factors for the development of albuminuria and renal impairment in type 2 diabetes. The Swedish Nation Diabetes Register (NDR). Nephrol Dial Transplant 2011, 26(4):1236-1243.

43. Katzmarzyk PT, Malina RM: Body size and physique among Canadians of First Nation and European ancestry. Am J Phys Anthropol 1999, 108: 161-172.

44. Katzmarzyk PT, Malina RM: Obesity and relative subcutaneous fat distribution among Canadians of First Nation and European ancestry. Int J Obes Relat Metab Disord 1998, 22:1127-1131.

45. Young TK, Sevenhuysen GP, Ling N, Moffatt ME: Determinants of plasma glucose level and diabetic status in a northern Canadian Indian population. CMAJ 1990, 142:821-830.

46. Mykkanen L, Haffner SM, Kuusisto J, Pyorala K, Laakso M: Microalbuminuria precedes the development of NIDDM. Diabetes 1994, 43:552-557.

doi:10.1186/1471-2458-12-290

Cite this article as: Zacharias et al: Prevalence, risk factors and awareness of albuminuria on a Canadian First Nation: A community-based screening study. BMC Public Health 2012 12:290.

\section{Submit your next manuscript to BioMed Central and take full advantage of:}

- Convenient online submission

- Thorough peer review

- No space constraints or color figure charges

- Immediate publication on acceptance

- Inclusion in PubMed, CAS, Scopus and Google Scholar

- Research which is freely available for redistribution 